\title{
Do written self-management plans improve asthma control? The evidence is not conclusive
}

\author{
Tony R Bai MD
}

\author{
"The most savage controversies are about matters as to which there is no good evidence either way." \\ - Bertrand Russell (1)
}

$\mathrm{T}$ hree components of asthma care have been promulgated by national asthma guidelines: patient education, regular review and written self-management plans. Unfortunately, the individual effects of each of these three components of a comprehensive asthma care program are difficult to separate. The available trials $(2-9)$ are too small and the results are too inconsistent, with potential biases in patient selection and withdrawals, and problems with data collection and analyses, for any firm conclusions to be made as to the contribution of written self-management plans.

In the trenches, beyond the world of efficacy studies in academia, the picture is rather bleak: the Asthma in Canada survey (10), involving 1001 randomly selected asthmatic participants, reported that only 19\% had received a written action plan. Jin et al (11) surveyed Canadian specialists and family physicians, and found that the majority of the Canadian physicians did not prescribe written action plans. Thus, it is clear that the adoption of written action plans in Canada has been poor. Why do physicians not follow guidelines? Qualitative research shows that action plans are actually unpopular with both patients and health care professionals. Jones et al (12) reported that almost all participants were ambivalent about the usefulness or relevance of written action plans. The variability of design and recommendations of peak flow-based plans reveals an uncertainty as to the correct advice, and many plans are confusing to patients and health professionals who are not experts in asthma care. The Asthma in Canada survey showed that only $11 \%$ of asthmatic patients who had an action plan recalled that it contained information on how to deal with a flare-up; clearly these data question the 'real world' effect of written plans. The first step on written plans is increased frequency and dose of inhaled corticosteroids (ICSs). Is this an evidence-based recommendation? The evidence is not overwhelming, and results of good studies have been negative (13). Even in a clinical trial setting, when oral prednisone was indicated according to the plan, patients were adherent only $56 \%$ of the time (14).
Peak flow plans are also imprecise - peak flow is well known both to underestimate the severity of outflow obstruction and to be relatively insensitive to major changes in the degree of airflow obstruction. Douglass et al (15) reported that some occupational groups are less likely to have selfmanagement plans, presumably reflecting perceived barriers by physicians to implementing plans in these groups. Interestingly, the most likely groups to have action plans were those least likely to need them! Most proponents of written asthma self-management plans propose that they should be targeted to those most at risk. These targeted groups include adolescents and young adults, who often will not or cannot read these plans. Health educators recommend that all printed material for health education be at a readability level of grade 5 or lower; however, not one of the national action plans meets this guideline, with a mean readability level of grade 8 (16). Furthermore, a recent, randomized, controlled trial of an asthma program, including a written action plan, in this high risk group showed no benefit (9).

Several decades ago, most patients were treated with shortacting, inhaled beta-agonists and oral, slow-release theophyllines, and asthma control was very poor in a substantial fraction of patients - action plans had much greater intuitive sense at that time. However, with improved education and improved therapy - first by improved ICSs (including improved steroids, devices and regimens) and then by combination devices of long-acting beta-agonists and ICSs - asthma control is now much easier to achieve. Thus, the theoretical need for widespread prescription of written action plans has diminished. Moreover, written self-management plans may be a surrogate for education, ie, their primary concern is reinforcing the need to take ICSs regularly. This was shown by Cote et al (6) - the single most important effect of an asthma education program based on self-management skills was adherence to ICS use. A similar inference can be drawn from the work of Suissa et al (17), using the Saskatchewan database - simply taking a low dose of inhaled steroids prevents asthma

University of British Columbia McDonald Research Laboratories, St Paul's Hospital, Vancouver, British Columbia

Correspondence: Dr Tony Bai, University of British Columbia McDonald Research Laboratories, St Paul's Hospital,

1081 Burrard Street, Vancouver, British Columbia V6Z 1Y6. Telephone 604 806-8704, fax 604 806-8351, e-mail tbai@mrl.ubc.ca 
death, and written action plans are not essential to achieve this key goal of education. Recently, the Laval groups (7) have shown that written action plans without structured education sessions are ineffective. Emergency room attendees discharged with a written plan and inhaler training showed no benefit in contrast to those taking part in a sophisticated education program (8).

Another problem with disseminating written selfmanagement plans is the lack of evidence that they have long term use. Despite regular review, adherence to peak flow monitoring falls off markedly over time. For example, Cote et al (18) showed that only $31 \%$ of patients were compliant with peak flow monitoring at 12 months. D'Souza et al (19) showed that six years after initiation of a widely used, credit card-sized action plan, only $41 \%$ of participants had used their written plan in the previous 12 months, versus $86 \%$ after two years. Only $29 \%$ had used a peak flow meter in the previous 12

\section{REFERENCES}

1. Russell B. The Problems of Philosophy. New York: Oxford University Press, 1959:46.

2. Cowie RL, Revitt SG, Underwood MF, Field SK. The effect of a peak flow-based action plan in the prevention of exacerbations of asthma. Chest 1997;112:1534-8.

3. Jones KP, Mullee MA, Middleton M, Chapman E, Holgate ST. The British Thoracic Society Research Committee. Peak flow based asthma self-management: a randomized controlled study in general practice. Thorax 1995;50:851-7.

4. Turner MO, Taylor D, Bennett R, Fitzgerald JM. A randomized trial comparing peak expiratory flow and symptom selfmanagement plans for patients with asthma attending a primary care clinic. Am J Respir Crit Care Med 1998; 157:540-6.

5. Charlton I, Charlton G, Broomfield J, Mullee MA. Evaluation of peak flow and symptoms only self management plans for control of asthma in general practice. BMJ 1990;301:1355-9.

6. Cote J, Cartier A, Robichaud P, et al. Influence on asthma morbidity of asthma education programs based on self-management plans following treatment optimization. Am J Respir Crit Care Med 1997;155:1509-14.

7. Lopez-Vina A, del Castillo-Arevalo F. Influence of peak expiratory flow monitoring on an asthma self-management education programme. Respir Med 2000;94:760-6.

8. Cote J, Bowie D, Robichaud P, Parent JG, Battisti L, Boulet LP. Evaluation of two different educational interventions for adult patients consulting with an acute asthma exacerbation. Am J Respir Crit Care Med 2002;163:1415-9.

9. Cowie RL, Underwood BN, Little CB, Mitchell I, Spier S, Ford GT. Asthma in adolescents: a randomized controlled trial of an asthma program for adolescents and young adults with severe asthma. Can Respir J 2002;9:253-9.

10. Glaxo Wellcome Inc. Asthma in Canada: A Landmark Survey. Mississauga: Glaxo Wellcome Inc, 2000. months (despite the free availability of these devices in New Zealand), compared with $73 \%$ after two years.

In conclusion, the widespread adoption of written action plans is not an evidence-based recommendation in 2002, a conclusion shared by the Heart, Lung, and Blood Institute National Asthma Education and Prevention Program (20) and a recent Cochrane review (21). Improvements in asthma education and therapy have reduced risk so that written plans have less potential value. The evidence suggests that there is a fundamental mismatch between the view of experts on who is a responsible asthma patient and what patients think that they should be doing to control symptoms. Written self-management plans for adults with mild to moderate asthma are unlikely to be accepted or sustained in primary care. The emphasis should be on an education strategy that ensures that patients have internalized simple strategies to initiate when asthma control deteriorates.

11. Jin R, Choi BC, Chan BT, et al. Physician asthma management practices in Canada. Can Respir J 2000;7:456-65.

12. Jones A, Pill R, Adams S. Qualitative study of views of health professionals and patients on guided self management plans for asthma. BMJ 2000;321:1507-10.

13. Fitzgerald JM, Becker A, Sears M, Mink S, Chung K, Lee J. A randomized, placebo-controlled trial of doubling the dose of maintenance budesonide versus continued maintenance therapy in patients experiencing asthma excacerbations. Am J Respir Crit Care Med. (In press)

14. Wraight J, Cowan J, Flannery E, Town G, Taylor R. Adherence to asthma self-management plans with inhaled corticosteroid and oral prednisone: A descriptive analysis. Respirology 2002;7:133-9.

15. Douglass J, Aroni R, Goeman D, et al. A qualitative study of action plans for asthma. BMJ 2002;324:1003-5.

16. Forbis, SG, Aligne CA. Poor readability of written asthma management plans found in national guidelines. Pediatrics 2002;109:e52.

17. Suissa S, Ernst P, Benayoun S, Baltzan M, Cai B. Low-dose inhaled corticosteroids and the prevention of death from asthma. N Engl J Med 2000;343:332-6.

18. Cote J, Cartier A, Malo J, Rouleau M, Boulet LP. Compliance with peak expiratory flow monitoring in home management of asthma. Chest 1998;113:968-72.

19. D'Souza WJ, Slater T, Fox C, et al. Asthma morbidity 6 years after an effective asthma self-management program in a Maori community. Eur Respir J 2000;15:464-9.

20. National Heart, Lung, and Blood Institute. Guidelines for the Diagnosis and Management of Asthma - Update on Selected Topics 2002. Executive Summary of the National Asthma Education and Prevention Program Expert Panel Report. Bethesda: National Institutes of Health, 2002.

21. Toelle BG, Ram FSF. Written individualised management plans for asthma in children and adults. Cochrane Database Syst Rev 2002;3:CD002171. (Review) 


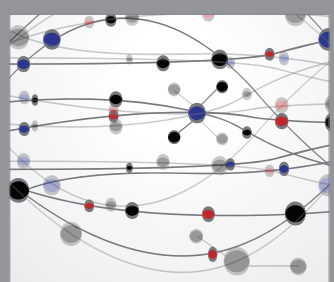

The Scientific World Journal
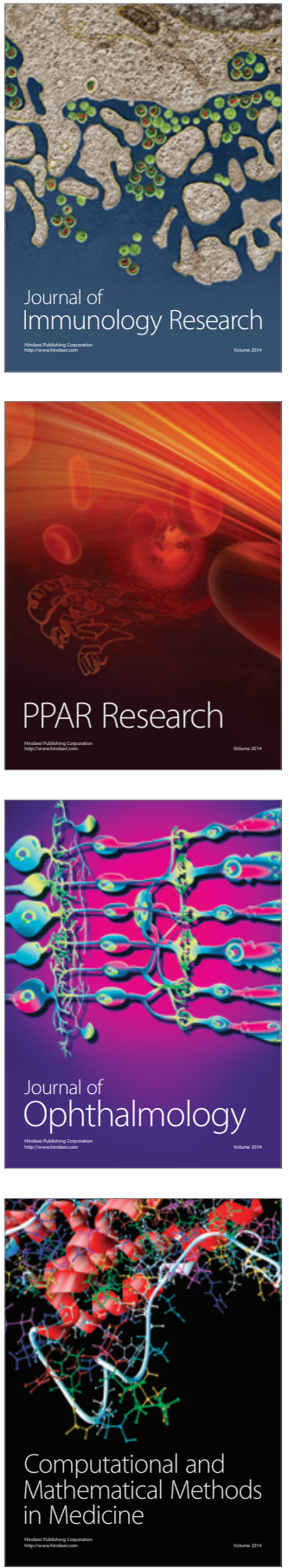

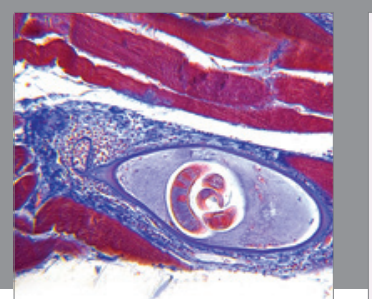

Gastroenterology Research and Practice

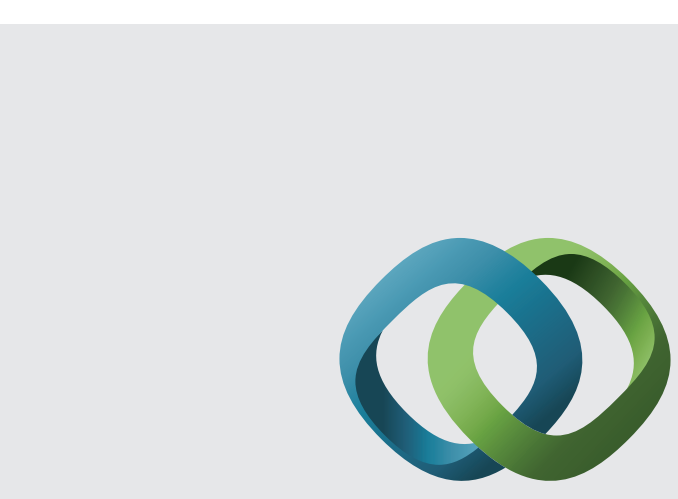

\section{Hindawi}

Submit your manuscripts at

http://www.hindawi.com
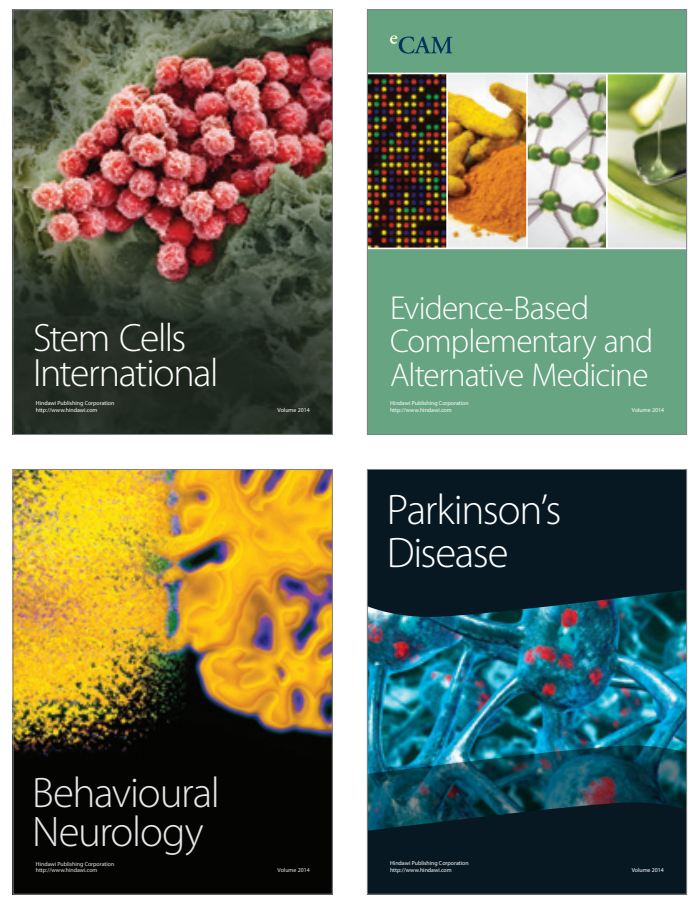


Disease Markers
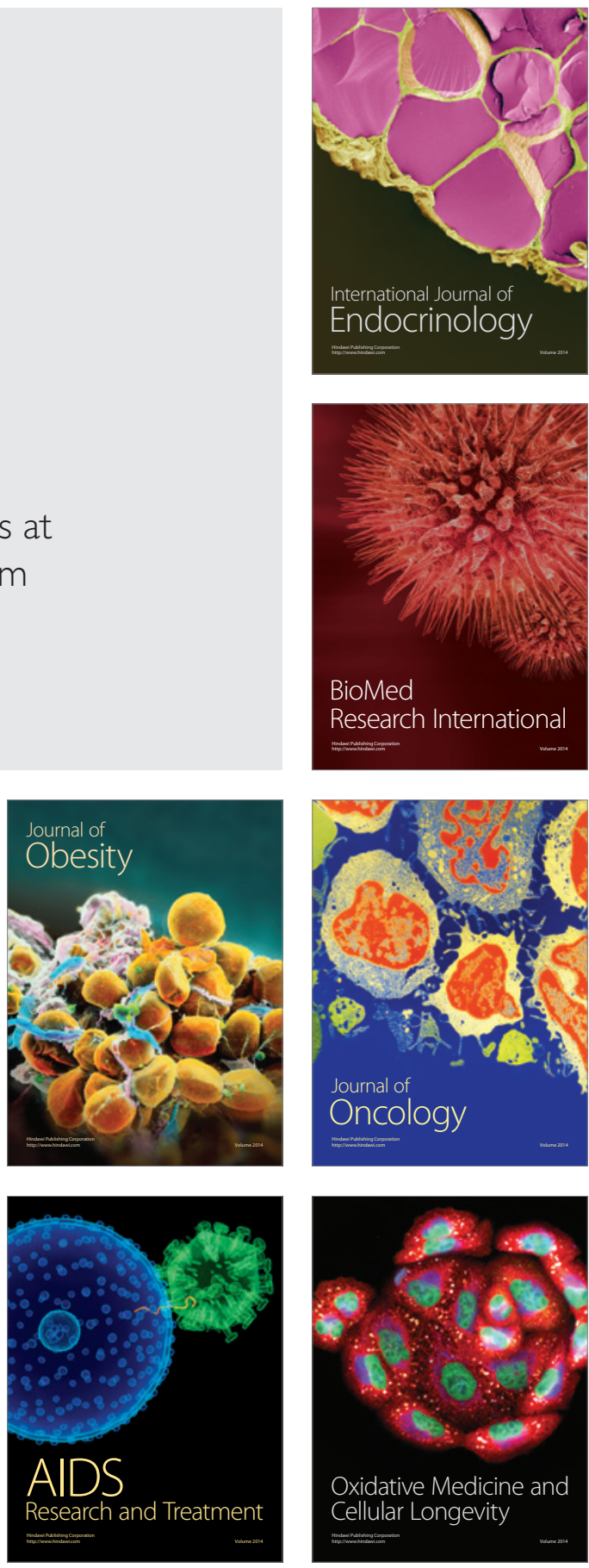